\section{Water Uptake Threshold of Rabbiteye (Vaccinium ashei) Blueberries and Its Influence on Fruit Splitting}

\author{
Donna A. Marshall ${ }^{1}$ and James M. Spiers \\ USDA-ARS, Thad Cochran Southern Horticultural Laboratory, P.O. Box \\ 287, Poplarville, MS 39470
}

\section{Kenneth J. Curry \\ University of Southern Mississippi, 118 College Drive \#5018, Hattiesburg, $M S$}

Additional index words. rabbiteye blueberry, Vaccinium ashei, water absorption, split-resistant, split-susceptible

\begin{abstract}
Split-resistant and split-susceptible rabbiteye blueberry fruit were evaluated at all stages of development to determine "water uptake thresholds" by soaking in distilled water. Weight increase after soaking was measured, and percent weight gain was calculated to take into consideration the weight increase of the fruit from development. The ratio of percent increase in volume to weight increase resulting from water uptake was calculated. Ratios of percent water uptake to weight increase between splitsusceptible 'Tifblue' and split-resistant 'Premier' blueberries were found to be similar. The split-susceptible 'Tifblue' had a $1.6 \mathrm{~g} / 50$ fruit increase with a $1.7 \%$ water uptake and a ratio of 1.08. 'Premier' had a higher weight increase with $3.3 \mathrm{~g} / 50$ fruit and also a higher percentage of water uptake at $3.6 \%$ providing a ratio of 1.09 . Although both absorbed water at a constant rate shown by a linear increase of weight increase over time, 'Premier' absorbed a significantly greater amount of water than did 'Tifblue' yet remained intact and did not split.
\end{abstract}

Rain-related splitting is a detriment to commercial blueberry growers in the southeastern United States. This problem has been reported to have reduced marketable yields and thus profit for these growers by up to $20 \%$ (Marshall et al., 2006). Researchers have been working on the problem of fruit splitting in various fruit crops for more than 70 years. If a few key factors that contribute to splitting in blueberries can be identified and implemented as screening tools for new cultivars, then long-term reductions in commercial blueberry fruit splitting are feasible.

Blueberries absorb external water either through the peel or through the pedicel. Yet some blueberry cultivars tend to absorb more water than the berry can sustain, thus resulting in fruit splitting. Studies have suggested many factors that influence fruit splitting. These factors include cultivar, fruit maturity, temperature of water (fruit splitting increases with an increase in water temperature), fruit temperature, period of wetting, soluble solids content, fruit firmness and turgor, relative humidity, soil moisture, peel permeability, and elasticity of the peel (Ackley and Krueger, 1980; Bullock, 1952; Gerhardt et al., 1945; Marshall, 1954; Powers and Bollen, 1947; Zielinski, 1964). It is generally agreed (Ackley and Krueger, 1980; Andersen and Richardson, 1982; Bullock,

Received for publication 9 July 2009. Accepted for publication 31 Aug. 2009.

${ }^{1}$ To whom reprint requests should be addressed; e-mail Donna.Marshall@ars.usda.gov.
1952; Davenport et al., 1972; Marshall, 1954) that the cause of cracking in cherries, whether directly or indirectly, is absorption of external water through the fruit peel. Therefore, protecting fruit from rainwater contacting and remaining on the fruit should reduce or eliminate splitting. However, Marshall (2001) found that covering blueberry plants to prevent rainfall from contacting the fruit was not sufficient to eliminate splitting. After a rainfall, split berries were harvested from both uncovered as well as covered plants. As expected, plants had significantly more split berries if left uncovered $(30.40 \%)$ than did covered plants $(19.90 \%)$. Yet some splits apparently occurred from uptake of water by the roots that is transported to the fruit by the xylem.

Susceptibility to splitting in cherries appears to be related to the rate and quantity of water uptake by the fruit (Belman and Keulemans, 1996). Uptake of water into the fruit occurs not only through the pedicel, but also through the peel. Lane et al. (2000) found that split-resistant cherry cultivars absorbed more water before splitting than did split-susceptible cherries. They concluded that water uptake thresholds at which fruit split was a major factor explaining the split susceptibility difference in cherry cultivars. Lane et al. (2000) added that a cultivar difference causally related to splitting susceptibility could be attributed to the amount of air-filled spaces between cells, which would allow water to be taken in without increasing fruit volume. This could be determined by measuring the ratio of percent water uptake to volume increase of resistant and susceptible cultivars. Ratios found to be similar suggest that cell adhesion might be an explanation for cultivar difference. Cultivars with cells weakly adhering to each other may split at lower turgor pressure than those with cells that strongly adhere.

A mature planting (30 plants of each cultivar) of 'Tifblue' and 'Premier' plants located at the Thad Cochran Southern Horticultural Laboratory in Poplarville, MS, was used for this study. Plants were divided into four replications of four plants/replication 'Tifblue' is a split-susceptible (SS) rabbiteye cultivar and 'Premier' is a split-resistant (SR) rabbiteye cultivar.

Expt. 1

During harvest season of 2002, sound fruit of 'Tifblue' and 'Premier' were collected at all stages of maturation from each plant of all replications (four samples of four plants). A 50 -fruit sample of each maturity stage (green, yellow, pink, purple, and ripe) was weighed recorded as initial dry weight. The entire sample was subjected to laboratory-induced splitting (Marshall et al., 2007). Fruit were

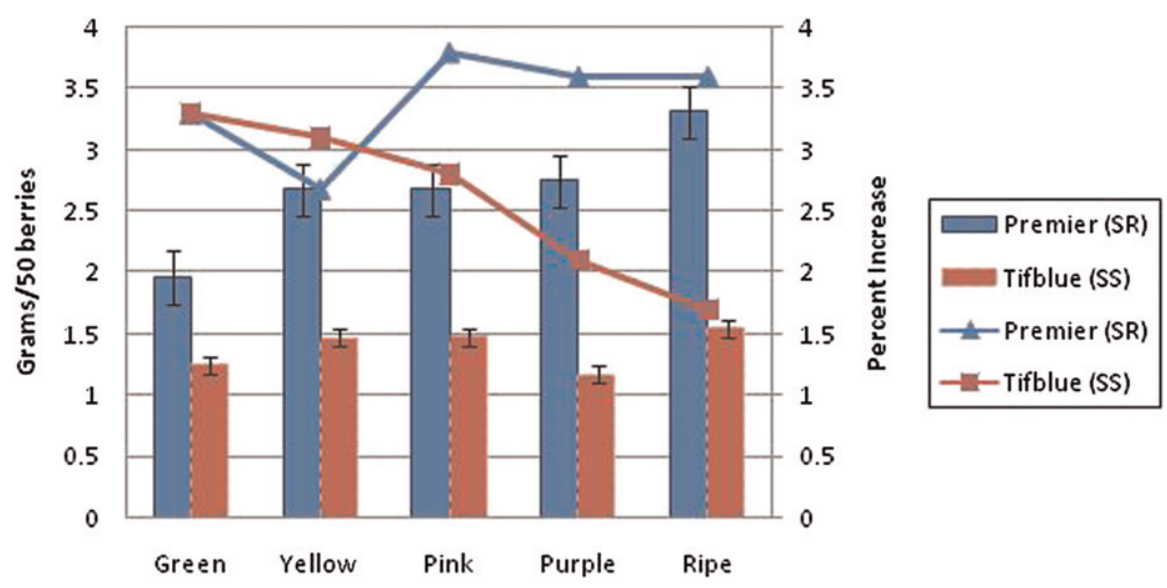

Fig. 1. Weight increase (bar) and percent increase (line) by water uptake of two blueberry cultivars. SR = split-resistant; SS = split-susceptible. Error bars represent SE of the mean $(n=50$. (percent increase $=$ weight increase/50 berry initial dry weight). 
placed into a glass beaker and covered with distilled water and left at room temperature overnight. After a 24-h interval, the fruit were removed from the water bath, blotted dry, reweighed, and observed for the presence of splitting. Percent split fruit was calculated.

Total water absorption by fruit was calculated at all stages of development by soaking in distilled water. Weight increase of 50 berries after soaking was measured and the percent weight increase was calculated (Fig. 1). The ratio of percent increase in weight to weight increase resulting from water uptake was calculated and graphically displayed (Fig. 2). Immature, green, 'Premier' berries absorbed $1.96 \mathrm{~g}$ of water $/ 50$ berries, a $3.3 \%$ increase in weight compared with $1.25 \mathrm{~g} / 50$ berries of 'Tifblue'. As the fruit matured to a yellow stage, 'Premier' berries absorbed significantly more water than green berries with an increase of $2.68 \mathrm{~g}$ or $2.7 \%$, whereas yellow 'Tiflue' berries had a $1.47 \mathrm{~g}$ or $3.1 \%$ weight increase. 'Premier' consistently absorbs more water as berries mature and increase in size. The percent weight increase in 'Premier' thus remains $\approx 3.6 \%$. This lends for a ratio that remains close to 1.0 (1.6 green, 1.0 yellow, 1.4 pink, 1.3 purple, 1.1 ripe). Conversely, 'Tifblue' absorbs a consistent ( $1.38 \pm 0.2 \mathrm{~g} / 50$ berries) amount of water regardless of size of fruit or maturity, giving 'Tifblue' an increasing lower percentage of fruit weight increase by water absorption. This lends for ratios that are higher in early development and approach 1.0 at ripe (2.6 green, 2.1 yellow, 1.9 pink, 1.8 purple, 1.1 ripe).

'Premier' (SR) had a higher percentage of split fruit than 'Tifblue' (SS) during the early stages of development (green-purple). Splitting occurrence was significantly higher in pink and purple stages, but never exceeded 16\% splits (Fig. 3). These 'Premier' fruit will likely drop off the plant and will never be harvested, posing little threat of rejection at the grading line because of split fruit. No splitting occurred in premature stages (greenpurple) of 'Tifblue' fruit, yet $26 \%$ splitting occurred when the fruit were completely ripe. Split ripe fruit causes a decrease in marketable fruit yield, and if significant numbers of fruit are present during grading, the entire batch could be rejected.

\section{Expt. 2}

In a separate soaking experiment, during 2002, 10 ripe fruit from each cultivar were weighed individually and subjected to the same laboratory-induced splitting technique in individual glass beakers. At 1, 2, $3,4,6$, and $24 \mathrm{~h}$, each individual fruit was removed, inspected, blotted, weighed, and if still intact, returned to the beaker of water. A final weight was recorded after $24 \mathrm{~h}$ of soaking. Total fruit weight increase resulting from water uptake was recorded. The ratio of percent increase in weight to weight increase resulting from water uptake was calculated.
Figure 4 shows the rate in which water is absorbed into ripe fruit. The absorption rate for both cultivars is linear throughout the 24-h period with 'Premier' showing an absorption rate at $3 \mathrm{mg} /$ hour $(r=0.9977)$ and 'Tifblue' absorption rate of $2.1 \mathrm{mg} /$ hour $(r=$

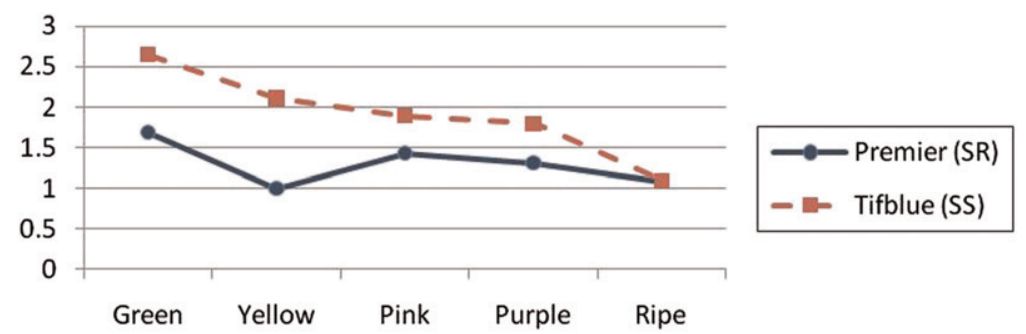

Fig. 2. Ratio of percent increase in volume to weight increase resulting from water uptake of two blueberry cultivars $(n=50)$

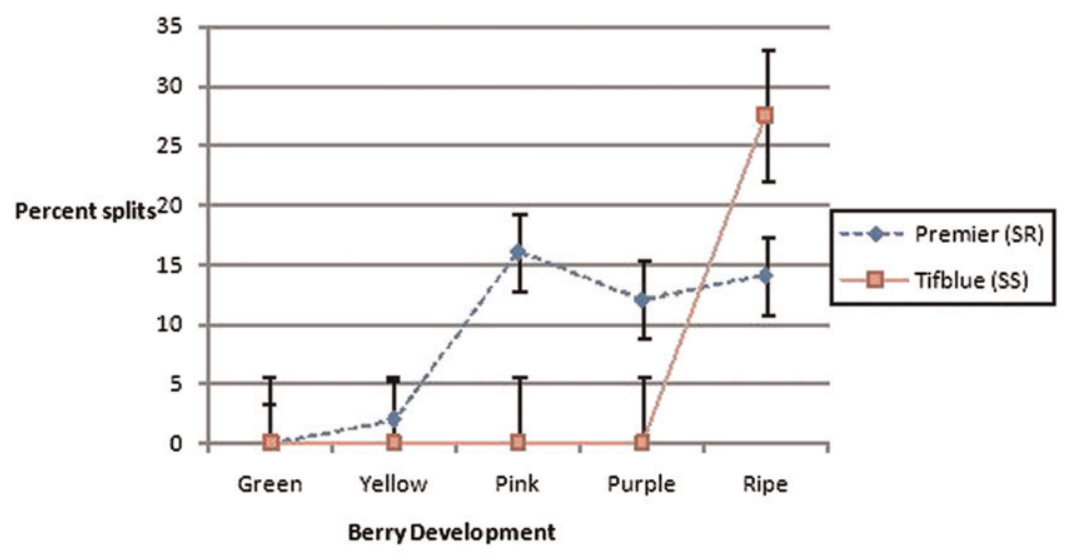

Fig. 3. Percent splits for two blueberry cultivars at each developmental stage occurring after soaking. Error bars represent the SE of the mean $(n=50)$.

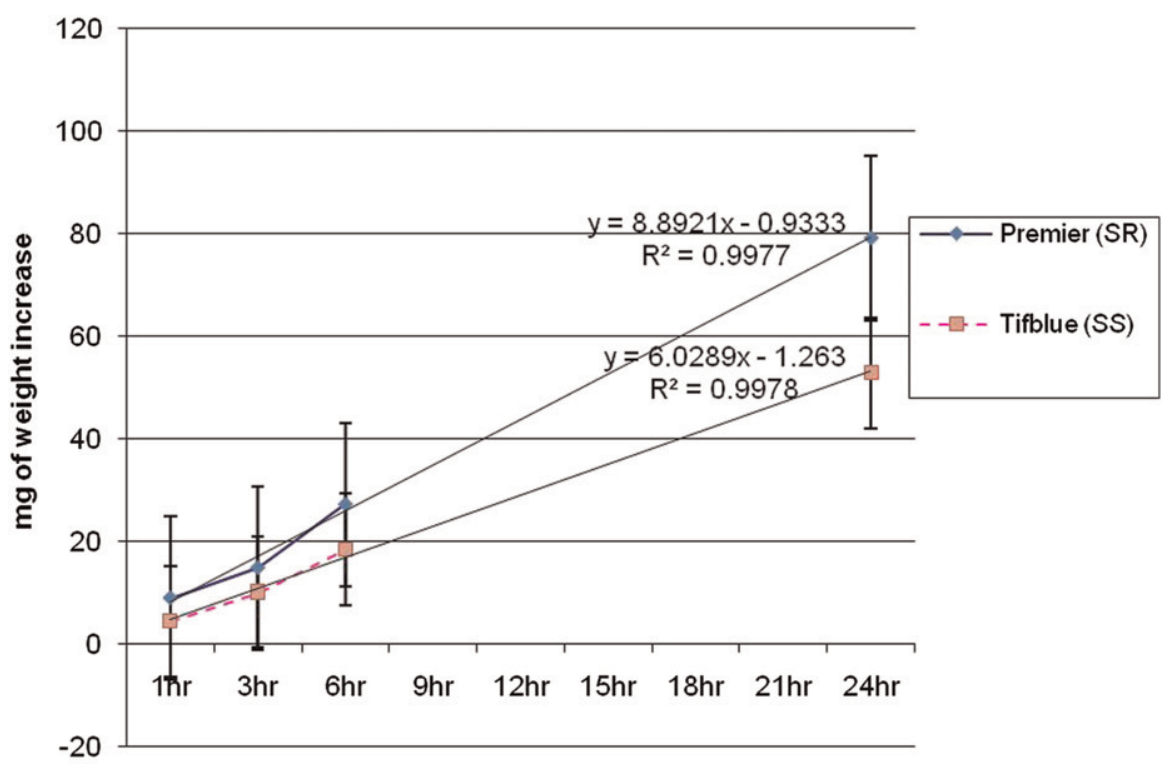

\section{Soaking Length}

Fig. 4. Weight increase resulting from soaking ripe blueberries in distilled water. Error bars represent SE of the mean $(n=10)$. 
before splitting than did SS cherries. This is also true of blueberries. 'Premier', a SR blueberry, absorbs more water than does 'Tifblue', yet 'Premier' remains intact and experiences minimal splitting. Lane et al. (2000) concluded that water uptake thresholds at which fruit split was a major factor explaining the difference in SR and SS cherry cultivars. They also added that "the basis for the cultivar difference could lie in the amount of air-filled spaces between cells, which would allow water to be taken in without increasing fruit volume. This could be determined by measuring the ratio of percent water uptake to volume increase of resistant and susceptible cultivars." Similar ratios would suggest that cell adhesion might be an explanation for cultivar difference. In this study, the ratios of percent water uptake:weight increase between SS and SR blueberries were found to be similar. The SS 'Tifblue' had a $1.6 \mathrm{~g} / 50$ fruit increase with a $1.7 \%$ water uptake. This would provide a ratio of 1.08 for 'Tifblue.' The SR 'Premier' had a higher weight increase with $3.3 \mathrm{~g} / 50$ fruit, but also a higher percentage of water uptake at $3.6 \%$ providing a ratio of 1.09 .

From this study and previous studies (Marshall, 2001; Marshall et al., 2006, 2007), rain-induced splitting is a cultivarspecific problem and the differences are evident from early development to maturity. This study further shows that both cultivars tested absorb water into the fruit at a linear rate. The difference is manifested in how the fruit contains the water that is absorbed. Are the cells filling and expanding past controllable capacity or are the cells remaining intact and the cell-to-cell adhesions giving way? This study does not answer these questions but does provide a starting point for further studies looking at cell-to-cell adhesion and possible air space within the pulp of the fruit. Adhesion points and air spaces need to be quantified and evaluated for possible causes of rain-related splitting in cultivated blueberries.

\section{Literature Cited}

Ackley, W.B. and W.H. Krueger. 1980. Overhead irrigation water quality and the cracking of sweet cherries. HortScience 15:289-290.

Andersen, P.C. and D.G. Richardson. 1982. A rapid method to estimate fruit water status with special reference to rain cracking of sweet cherries. J. Amer. Soc. Hort. Sci. 107:441444.

Belman, K. and J. Keulemans. 1996. A study of some fruit skin characteristics in relation to the susceptibility of cherry fruit to cracking. Acta Hort. (ISHS) 410:547-550.

Bullock, R.M. 1952. A study of some inorganic compounds and growth promoting chemicals in relation to fruit cracking of Bing cherries at maturity. Proc. Amer. Cos. Hort. Sci. 59:243253
Davenport, D.C., K. Uriu, and R.M. Hagen. 1972. Antitranspirant film: Curtailing intake of external water by cherry fruit to reduce cracking. HortScience 7:507.

Gerhardt, F., H. English, and E. Smith. 1945. Cracking and decay of 'Bing' cherries as related to the presence of moisture on the surface of the fruit. Proc. Amer. Soc. Hort. Sci. 46:191198.

Lane, W.D., M. Meheriuk, and D.L. McKenzie. 2000. Fruit cracking of susceptible, and intermediate, and a resistant sweet cherry cultivar. HortScience 35:239-242.

Marshall, D.A. 2001. Incidence of splitting in 'Premier' and 'Tifblue' rabbiteye blueberries. Master's Thesis. University of Southern Mississippi, Hattiesburg, MS

Marshall, D.A., J.M. Spiers, and J.H. Braswell. 2006. Splitting severity among rabbiteye ( Vaccinium ashei Reade) blueberry varieties in Mississippi and Louisiana. Intl. J. Fruit Sci. 6:77-81.

Marshall, D.A., J.M. Spiers, S.J. Stringer, and K.J. Curry. 2007. Laboratory method to estimate rain-induced splitting in cultivated blueberries. HortScience 42:1551-1553.

Marshall, R.E. 1954. Cherries and cherry products. Interscience Publishers, Inc., New York, NY. p. $60-63$.

Powers, W.L. and W.B. Bollen. 1947. Control of cracking of fruit by rain. Science 105:334-335.

Zielinski, Q.B. 1964. Resistance of sweet cherry varieties to fruit cracking in relation to fruit and pit size and fruit color. Proc. Amer. Soc. Hort. Sci. 84:98-102. 